Proceedings of the 2005 Winter Simulation Conference

M. E. Kuhl, N. M. Steiger, F. B. Armstrong, and J. A. Joines, eds.

\title{
MODELING EMERGENCY DEPARTMENTS USING DISCRETE EVENT SIMULATION TECHNIQUES
}

\author{
Alexander Komashie \\ School of Design and Engineering, Systems Engineering \\ Research Group (SERG) \\ Brunel University \\ Uxbridge, Middlesex \\ London, UB8 3PH, U.K.
}

\author{
Ali Mousavi. \\ School of Design and Engineering, Systems Engineer- \\ ing Research Group (SERG) \\ Brunel University \\ Uxbridge, Middlesex \\ London, UB8 3PH, U.K.
}

\begin{abstract}
This paper discusses the application of Discrete Event Simulation (DES) for modeling the operations of an Emergency Department (ED). The model was developed to help the ED managers understand the behavior of the system with regard to the hidden causes of excessive waiting times. It served as a tool for assessing the impact of major departmental resources on Key Performance Indicators, and was also used as a cost effective method for testing various what-if scenarios for possible system improvement. The study greatly enhanced managers' understanding of the system and how patient flow is influenced by process changes and resource availability. The results of this work also helped managers to either reverse or modify some proposed changes to the system that were previously being considered. The results also show a possible reduction of more than $20 \%$ in patients' waiting times.
\end{abstract}

\section{INTRODUCTION}

The creation of the National Health Service (NHS) in 1948 was an extraordinary act of emancipation for people of Britain: no longer would wealth determine access to healthcare (Tony Blair 2000). The NHS has since delivered many major improvements in heath but still falls short of the standards patients expect (NHS plan 2000). The government has therefore made a commitment to provide the necessary resources for modernizing the service by the year 2010. The whole of the NHS and its staff have been challenged to pursue a patient led service modernization. To this effect several performance targets have been set (DoH 2002). The key factors that influence performance are queue lengths and waiting times of patients particularly in the Emergency Departments (EDs).

The ED under study is one of the busiest in the London area. It serves about 70,000 patients annually. Like other EDs in Britain, it has been working hard towards the achievement of the NHS waiting time targets.
In a recent assessment report published by the Commission for Health Improvement (CHI, Ratings 2003), this ED was ranked out of the top $20 \%$ in comparison with similar departments. The report also revealed that 38 percent of patients that visited the department had to wait for more than four hours and 22 percent waited between two and four hours. Furthermore, $31 \%$ of patients had to wait for more than 1 hour following arrival before being examined by a doctor.

Following interviews with the department's managers, it was noticed that from their point of view, the department's capacity and demand were well understood. They also believed that they had enough capacity for the demand; however there had always been about $10 \%$ variability on system performance. According to the managers, this variability has been due to capacity-demand mismatch. As will be seen, this work has shown that this was not the only reason for performance variability. Discrete Event Simulation (DES) was proposed as appropriate for this modeling task.

DES has been used in EDs for modeling operations and for the analysis of patient flows and throughput time (Blasak et al. 2003; Samaha et al. 2003; Mahapatra et al. 2003 and Takakuwa et al. 2004). Others have used DES for estimating future capacities of new ED facilities or expansions (Baesler et al. 2003; Wiinamaki et al. 2003). In taking advantage of the flexibility of DES researchers have integrated simulation with other techniques like Integer Linear Programming (ILP), Six Sigma etc for specific applications (Centeno et al. 2003; Miller et al. 2003; Baesler et al. 2001). Hospital managers are under pressure to come up with ways to improve operations (Sinreich et al. 2004) and this pressure is ever increasing.

The main objectives of the present work are to model the system for better understanding of operations, to determine the impact of critical resources on Key Performance Indicators (KPIs) and to provide a cost effective means of testing various scenarios for possible system improvement. 


\section{Komashie and Mousavi}

The next section presents a brief description of the system. Section three describes the model's construction, section four presents some experiments and results and finally in section five we draw the conclusions to this work.

\section{SYSTEM DESCRIPTION}

The physical layout of the department is shown in figure 1. There are four possible entrances or exits to the department but for the purpose of this work, only two were considered. These are shown as walk-in and ambulance entry in figure 1.

Patients move through various sections of the department depending on the type of care they require. The main sections are the reception, Minor Assessment Area (Minors), Major Assessment Area (Majors), Resuscitation (Resus.), Pediatrics (Peds.), Medical Assessment Unit (M.A.U.), an X-ray room and the mental health liaison team (M.H.L.T.).

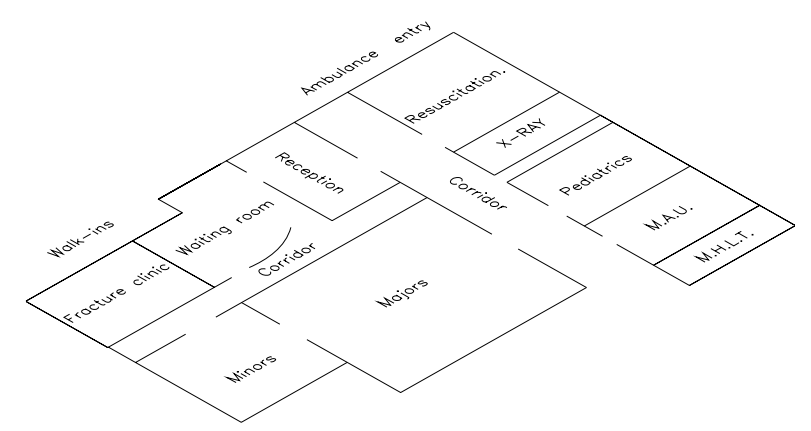

Figure 1: Physical layout of the ED

\subsection{Departmental Resource Definition}

The main resources in the department were defined as: doctors, nurses and beds. The doctors in the department fall within the following categories and in descending order of ranking:

1. Consultants

2. Registrars

3. Staff Grades (SG)

4. Senior House Officers (SHO.)

5. House Officers (HOs)

The ranking is closely related to the ability to work without supervision. This ranking has an effect on resource allocation and decision making.

Based on observations, it takes SHOs $25 \%$ extra time to process patients, in comparison with SGs. Similarly, the following grades of nurses also exist in the department:

1. G - Grades. - Senior Sisters.

2. F - Grades. - Sisters.

3. E - Grades - Staff Nurses.

4. D - Grades - Nurses.

\section{MODEL CONSTRUCTION}

The simulation model was developed using the Arena Simulation software from Rockwell Automation. The input data were analyzed using the Arena input analyzer. Various features of the system captured by the model include queues, various levels of pre-emptive priority among patients, multiple "server" (doctors and nurses) with variable service times depending on patient condition and nonstandard distributions of patient arrivals.

Figure 2 shows an overview of the simulation model. The layout was developed using AutoCAD 2004 software and imported into the Arena simulation environment for the animation.

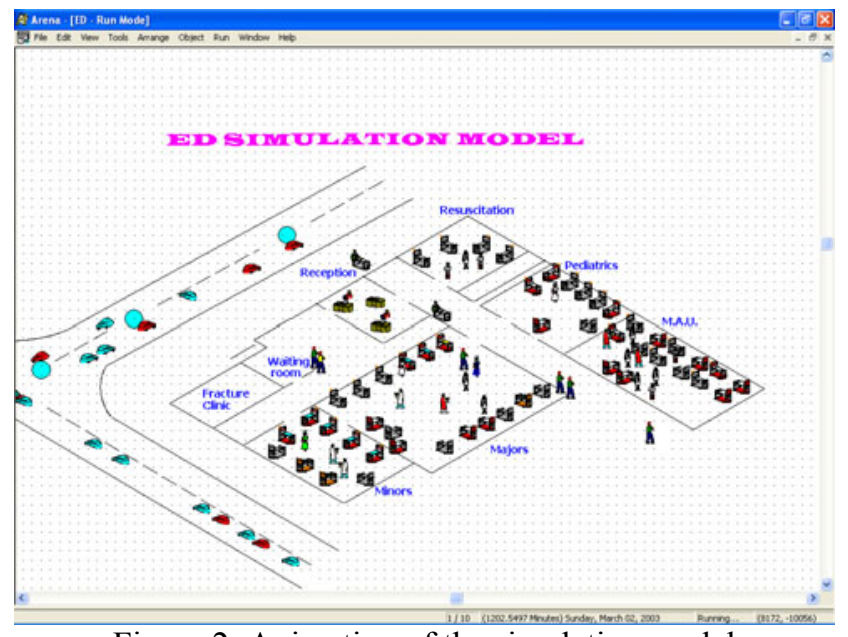

Figure 2: Animation of the simulation model

\subsection{Model Scope and Level}

Research has shown that in most cases, $80 \%$ of model accuracy is obtained from only $20 \%$ of the model's detail, (Robinson 1994). It was therefore desired to model the minimum amount of detail required to achieve the project's objectives. From the physical layout of the system shown in figure 1 , it is evident that not all sections of the department have been modeled. The model scope was limited to six (6) main areas that interact most as can be seen in figure 2.

While considering the scope and level of the model, it is important to note the external influences that cause "blockage" in the ED. Figure 3 shows the influence of main hospital admissions on the ED. Arriving patients enter the ED and leave as discharged or admitted. Admissions are either direct to the hospital wards or referred to the M.A.U. or the Observations ward (Obs.) which is within the M.A.U. For each movement along the admissions route, there is an amount of delay that sum up to cause the "blockage" experienced in the ED. 


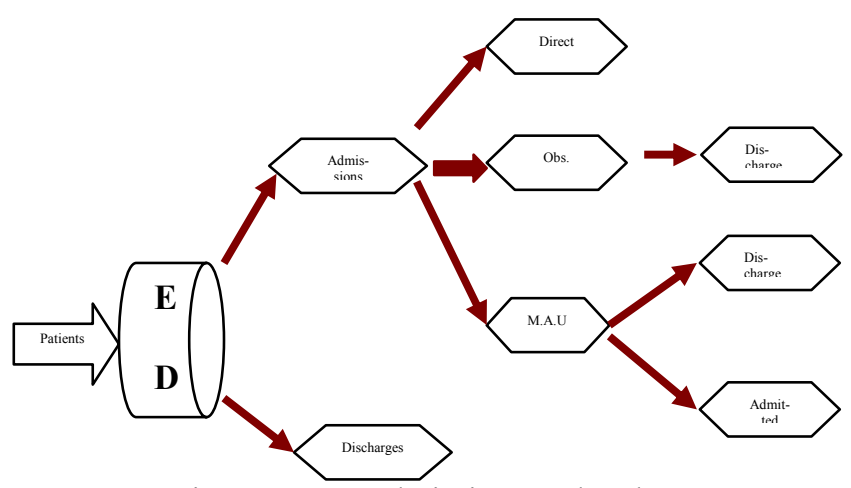

Figure 3: ED Admissions and Delays

\subsection{Data Collection}

The information regarding patients' processing time were unavailable and had to be collected by frequent observations. In addition, the percentage of patients requiring particular care needed to be extracted from a combination of stored data and regular observations. Other helpful sources of information were the interviews, and questions that were answered by the staff during the study. With regards to patients arrivals however, the hospital data base was very helpful for information on the approximately 6000 patients modeled within the simulation period. Figure 4 shows the arrival distributions for patients on various days of the week.

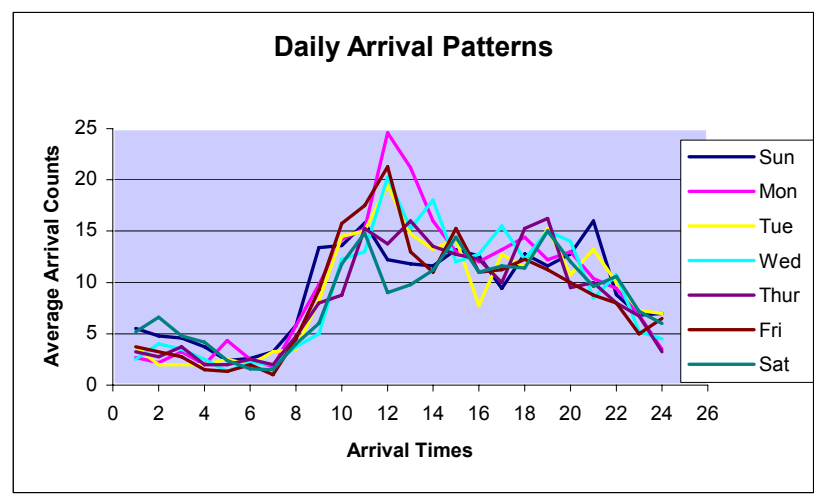

Figure 4: Daily patient arrival rate

The hospital bed management department provided data on admissions. This data were analyzed using the Arena input analyzer and the results provided insight to the impact of the admission delays. The analysis showed that the admissions impose a delay of GAMM $(106,1.16)$ minutes on the ED.

\subsection{Verification, Validation and Testing (VV\&T)}

Throughout the development of this model, the informal, static and dynamic techniques for verification, validation and testing were employed as described in Banks (1998).

The model was shown to the ED managers and values of the Key Performance Indicators (KPIs) such as queue length and waiting times were compared to current system values or judged by the experience of managers before accepting the model as valid. The model animation was extremely helpful at this stage of the project.

\section{EXPERIMENTS AND RESULTS}

The ED managers indicated at the beginning of the work that the key resources in the department were doctors, nurses and beds. For this reason it was decided to assess the impact of changes in these resources on the performance of the system. It was also observed during the course of the study that admissions had some impact on the ED process but it was not well understood and was therefore intended for investigation. Finally, there was a fracture clinic next to the ED with six (6) beds that may be available to the "Minors" section after $2 \mathrm{pm}$ each day. The management wanted to know what impact this may have on performance. In view of these, the following scenarios were designed.

- $\quad$ Scenario 0 - System as it is (As Is Scenario)

- Scenario 1 - Adding a bed each to "Minors" and "Majors"

- Scenario 2 - Adding a nurse each to "Minors" and "Majors"

- Scenario 3 - Adding a doctor each to "Minors" and "Majors"

- Scenario 4 - Assumed system without 'blockage' due to admissions

- Scenario 5 - Using six (6) beds (or cubicles) in Fracture clinic for "Minors" after 2 pm each day.

\subsection{Lengths of Stay and Queuing Times}

Figure 5 shows the total time or length of stay and bed (or cubicle) queuing time for "Minors" and "Majors" patients as they changed across the various scenarios. For the original system (scenario 0), the total times were 249minutes and 182minutes for "Majors" and "Minors" respectively. "Minors" patients had to a wait in a queue for about 72 minutes. This was about 10 minutes in 'Majors'. 


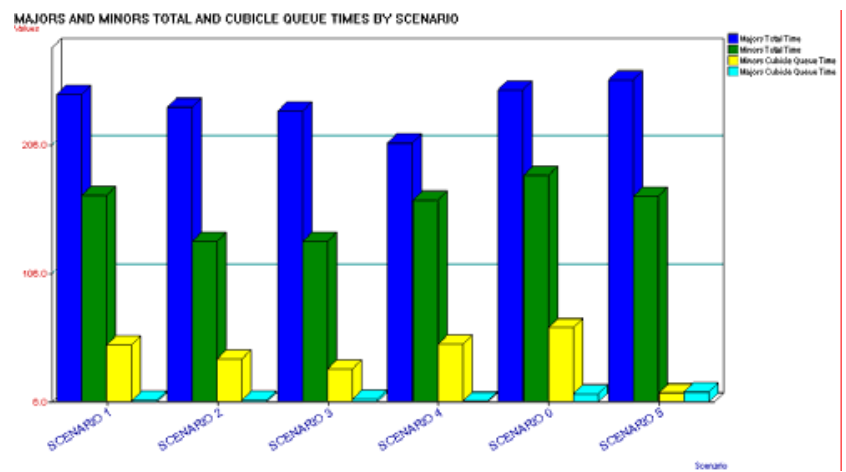

Figure 5: Total time and bed (cubicle) queuing time for "Minors" and "Majors"

The highest reduction in total time for "Majors" patients was about 17 percent. This occurred in scenario 4 when the "blockage" was removed. Additions of nurses and doctors to "Majors" caused very little changes in the total time values indicating there was enough capacity to meet demand if external factors are fully eliminated.

The most significant improvement in total time for "Minors" patients happened in scenarios 2 and 3. These resulted in about 28 percent reduction in total time and about 57 percent reduction in queuing time for beds (or cubicles). It is interesting to note that whilst in scenario 5 six (6) extra beds (or cubicles) in the fracture clinic were made available to "Minors", the improvement in total time was not much different from that achieved from scenario 1 where only a cubicle was added. However, scenario 5 reduced the "Minors" queue times for beds (or cubicles) by about 83 percent. This result is best described as moving the queues from the waiting room into the cubicles - as was noticed in the resulting increase in the waiting times for nurses and doctors of about 63 percent and 21 percent respectively.

Further analysis revealed that total times in "Minors" were much more sensitive to the number of nurses and doctors than to admission delays or the number of cubicles. It could be noticed that this gain due to increased number of doctors and nurses "Minors" also resulted in some loss in utilization of these key resources.

\subsection{Resource Schedules and Utilization}

Figure 6 shows the resource schedules and availability depending on the time of day during the simulation run. As managers observe changes in queues and changes in the resource schedules at various times of the day, they get a good understanding of how various parts of the system interact.

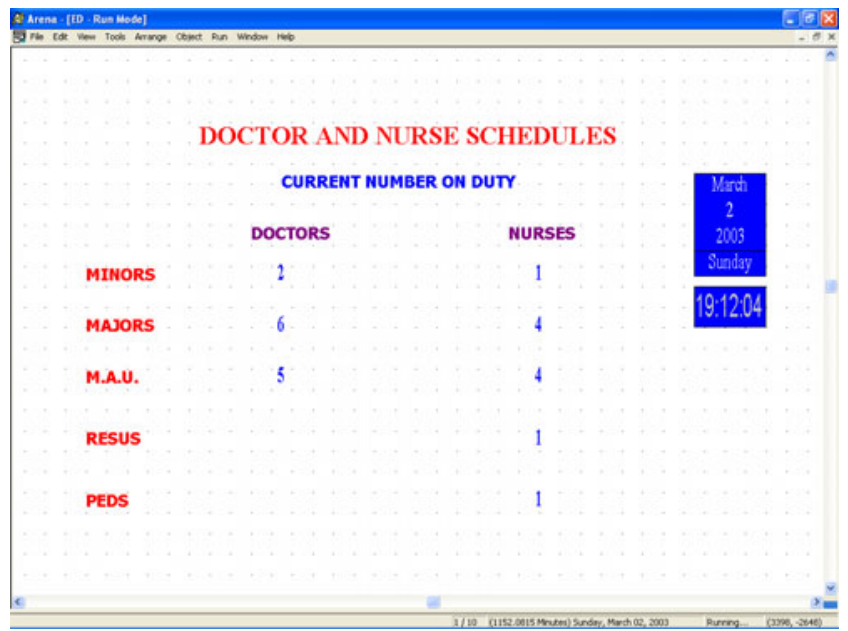

Figure 6: Doctor and nurse schedules during simulation run

A comparison of figure 5 with figure 7 indicates precisely how the utilization of nurses and doctors varies with queue lengths and times. It has been observed here that excessive waiting time is partly an indication of overwhelmed resources or high utilization.

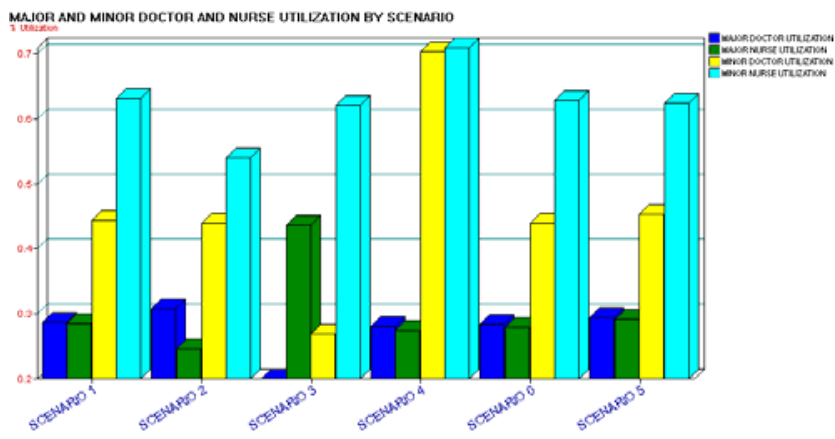

Figure 7: Doctor and nurse utilization in 'Majors' and 'Minors'

\section{CONCLUSIONS}

The simulation model described in this work allowed the department to perform risk-free what-if analyses on departmental operations for waiting time reduction, as well as experimentations on scheduling policies.

The results have shown that patient total times in the present system are 249minutes and 182minutes for "Majors" and "Minors" respectively. It has also been observed that total time in "Minors" is more sensitive to the number of nurses and doctors than in "Majors". This is evident in the test of adding a nurse or doctor to "Minors" which reduced the total time of patients by 28 percent.

Using the fracture clinic for "Minors" after $2 \mathrm{pm}$ each day reduced the queuing time for cubicles in 'Minors' by about 83 percent but patient total time went down by only about 9 percent. This confirms that the decision in itself may not be very helpful. However, implementing this with 
an additional doctor or nurse would yield a much better result.

The experiments have also shown that eliminating "blockage" due to lack of beds in main hospital wards could greatly enhance patient flow especially in the "Majors' section.

\section{REFERENCES}

Baesler F. Felipe, Jahnsen E. Hector and Da Costa Mahal, 2003. The use of simulation and design of experiments for estimating maximum capacity in an emergency room. In Proceedings of the 2003 Winter Simulation Conference, S. Chick, P. J. Sanchez, D. Ferrin, and D. J. Morrice (eds), 1903-1906.

Banks Jerry (1998), Handbook of Simulation - Principles, Methodology, Advances, Applications and Practices, New York, John Wiley and Sons Inc., 0471134031.

Blasak E. Ruby, Starks W. Darrell, Armel S. Wendy and Hayduk C. Mary, 2003. The use of simulation to evaluate hospital operations between the emergency department and a medical telemetry unit. In Proceedings of the 2003 Winter Simulation Conference, S. Chick, P. J. Sanchez, D. Ferrin, and D. J. Morrice (eds), 1887-1893.

Centeno A. Martha, Giachetti Ronald, Linn Richard, and Ismail M. Abdullah, 2003. A simulation-ILP based tool for scheduling ER staff. In Proceedings of the 2003 Winter Simulation Conference, S. Chick, P. J. Sanchez, D. Ferrin, and D. J. Morrice (eds), 19301938.

Commission for health Improvement, CHI (now Healthcare Commission), ratings 2003, Available via $<$ http://ratings2003.healthcarecommission.org.uk/ratin gs/> [accessed December, 2003].

Department of Health (DoH), September 2002, Improvement, Expansion and Reform: The next three years. Priorities and Planning Framework, 2003-2006, available via <http://www.dh.gov.uk/Home/fs/en> [accessed July, 2005].

Department of Health (DoH), July 2000, The NHS plan, available via $<$ http://www.dh.gov.uk/Home/fs/en $>$ [accessed March, 2005].

Mahapatra S., Koelling C. P., Patvivatsiri L., Fraticelli B. Eitel D., and Grove L., 2003. Pairing emergency severity index5-level triage data with computer aided system design to improve emergency department access and throughput. In Proceedings of the 2003 Winter Simulation Conference, S. Chick, P. J. Sanchez, D. Ferrin, and D. J. Morrice (eds), 1917-1925.

Miller J. Martin and Ferrin M. David, 2003. Simulating six sigma improvement ideas for a hospital emergency department. In Proceedings of the 2003 Winter Simulation Conference, S. Chick, P. J. Sanchez, D. Ferrin, and D. J. Morrice (eds), 1926-1929.
Robinson Stewart, (1994), Successful Simulation - A Practical Approach to Simulation Projects, England, McGraw-hill Book Company Europe, 0-07-707622-2.

Samaha Simon, Armel S. Wendy and Starks W. Darrell, 2003. The use of simulation to reduce the length of stay in an emergency department. In Proceedings of the 2003 Winter Simulation Conference, S. Chick, P. J. Sanchez, D. Ferrin, and D. J. Morrice (eds), 19071911.

Takakuwa Soemon and Shiozaki Hiroko, 2004. Functional analysis for operating emergency department of a general hospital. In Proceedings of the 2004 Winter Simulation Conference, R. G. Ingalls, M. D. Rossetti, J. S. Smith, and B. A. Peters (eds), 2003-2011.

Tony Blair, July 2000, In forward to The NHS plan, available via <http://www.dh.gov.uk/Home/fs/en> [accessed March, 2005].

Wiinamaki Allan and Dronzek Rainer, 2003. Using simulation in the architectural concept phase of an emergency department design. In Proceedings of the 2003 Winter Simulation Conference, S. Chick, P. J. Sanchez, D. Ferrin, and D. J. Morrice (eds), 1912-1916.

\section{AUTHOR BIOGRAPHIES}

ALEXANDER KOMASHIE is a PhD Research Student in the School of Engineering and Design at Brunel University. His research interests include health care systems modeling and simulation for improving patient satisfaction and decision making. His e-mail address is $<$ Alexander.Komashieabrunel.ac.uk> .

ALI MOUSAVI, Dr is a Lecturer in the School of Engineering and Design at Brunel University. His research interests include simulation modeling and analysis, especially techniques to improve simulation analysis in practical applications. His e-mail address is $<$ Ali.Mousavi@brunel.ac.uk> and his Web address is <www.brunel.ac.uk/ emstaam>. 